\title{
PET-MRI crucial role in the diagnostic work-up of pan- medullary astrocytoma
}

\author{
Diego Cecchin ${ }^{1,2 *}$, Alessandro Della Puppa ${ }^{3}$, Marina Paola Gardiman ${ }^{4}$, Mariagiulia Anglani ${ }^{5}$ and Chiara Briani ${ }^{6}$ \\ ${ }^{1}$ Nuclear Medicine Unit, Department of Medicine, University-Hospital of Padova, Italy \\ ${ }^{2}$ Padua Neuroscience Center, University of Padova, Italy \\ ${ }^{3}$ Neurosurgery, Hospital of Padova, Italy \\ ${ }^{4}$ Unit of Surgical Pathology and Cytopathology Department of Medicine, University Hospital of Padova, Italy \\ ${ }^{5}$ Neuroradiology Unit, Hospital of Padova, Italy \\ ${ }^{6}$ Neurology Unit, Department of Neurosciences, University of Padova, Italy
}

\section{Case report}

A 62-year-old man on immunosuppressive therapy because of heart transplant 15 years before, presented with progressive paraparesis, sensory loss with T10 level, lower limbs areflexia and sphincteric abnormalities.

A spinal MRI (T1 and T2 weighted) showed spinal cord swelling without contrast-enhancement. Because of the doubtful MRI results and the lack of a precise target site for biopsy a ${ }^{18} \mathrm{~F}$-FDG PET/MRI was proposed to the patient in order to better clarify the nature of the lesion.

A limited number of papers [1-2] describing small case series of spinal cord tumors (using ${ }^{18} \mathrm{~F}-\mathrm{FDG}$ or ${ }^{11} \mathrm{C}$-Methionine PET/CT alone or combined to MRI) reports a variable degree of uptake of lesions partially corresponding to the area of constrast enhancement. Plasma glucose was $108 \mathrm{mg} / \mathrm{dL}$ before PET acquisition (performed about 60 minutes after injection of $170 \mathrm{MBq}$ of ${ }^{18} \mathrm{~F}-\mathrm{FDG}$ ). PET images were reconstructed using Dixon sequence for attenuation correction.

PET-MRI (T2, T1, with and without fat saturation) showed diffuse irregular spinal uptake of ${ }^{18} \mathrm{~F}$-FDG (Figure1) without areas of clear, high focal uptake. A pan-medullary tumor was then suspected because no increased uptake of ${ }^{18} \mathrm{~F}$-FDG is physiologically evident in the normal spinal cord and because no other traumatic, inflammatory or infective clinical data explained PET data. Caudally to D10-D11 level the uptake of ${ }^{18} \mathrm{~F}-\mathrm{FDG}$ was however slightly lower and therefore spinal cord biopsy was performed at D9 level (Figure2).

Histology showed low-grade astrocytoma (grade II, WHO classification) (Figure 3-4). Primary pan-medullary tumors are rare, and the diagnosis is challenging. In our case combined ${ }^{18} \mathrm{~F}$-FDG PETMRI was crucial to confirm the clinical suspect and to plan the site of spinal cord biopsy.

Compliance with ethical standards

\section{Funding}

This study was NOT funded by grants.

\section{Conflict of interest}

All the authors declare that they have no conflict of interest.

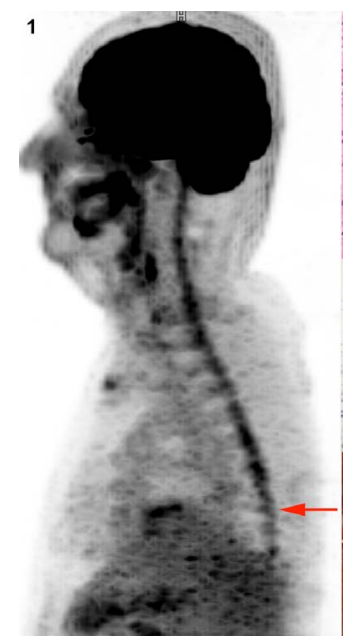

Figure 1. Diffuse spinal ${ }^{18}$ F-FDG uptake (MIP, sagittal). Arrow: site of surgery.

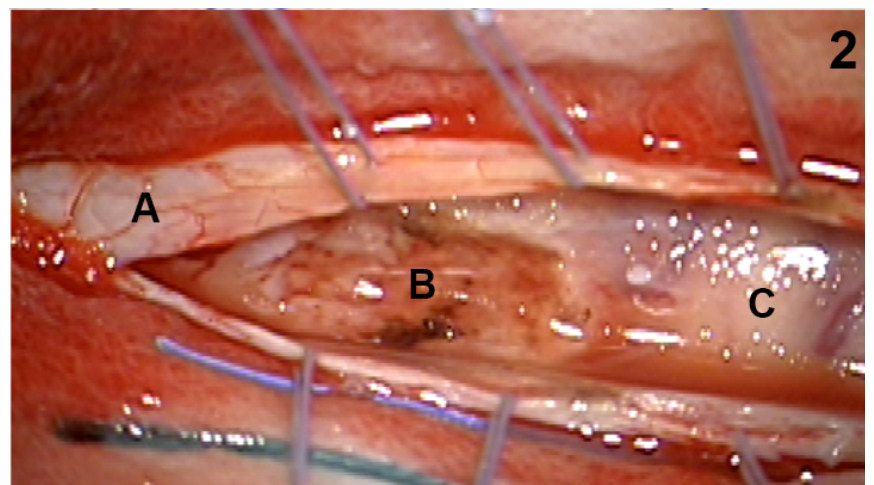

Figure 2. Intra-operative view after T9-T10 laminectomy: congested diffusely infiltrated spinal cord (A: dura; B: surgical cavity; C: spinal cord).

${ }^{\star}$ Correspondence to: Cecchin Diego, MD, Department of Medicine - DIMED, Unit of Nuclear Medicine - University of Padova, Via Giustiniani, 2, 35128 Padova - Italy, Tel: +39-049 821 1310; E-mail: diego.cecchin@unipd.it

Received: August 19, 2018; Accepted: August 24, 2018; Published: August 31, 2018 


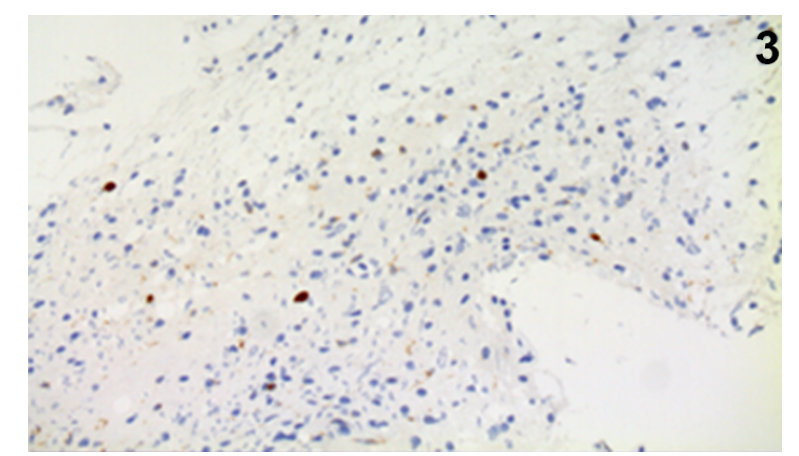

Figure 3. Immunohistochemistry (X40): MIB1 cells reactivity in scattered, atypical nuclei

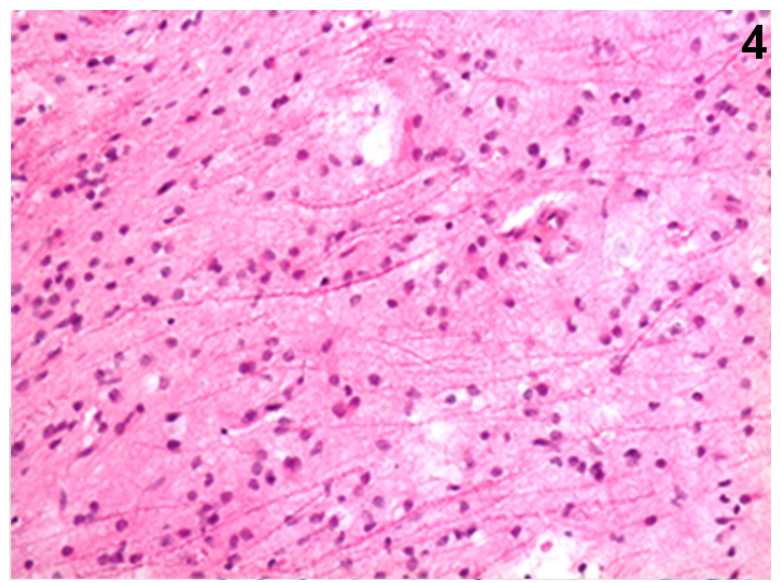

Figure 4. Histopathology (H\&E X40): neoplastic astrocytes with large and hyperchromatic nuclei

\section{Statement of human rights}

All procedures performed in studies involving human participants were in accordance with the ethical standards of the institutional and/ or national research committee and with the 1964 Helsinki declaration and its later amendments or comparable ethical standards.

\section{Informed consent}

Informed consent was obtained from all individual participants included in the study.

\section{Individual contributions of the authors}

Chiara Briani is the neurologist in charge of the patient.

Alessandro Della Puppa is the neurosurgeon who performed the spinal cord biopsy.

Diego Cecchin is the nuclear medicine physician who performed and interpreted the PET-MRI.

Mariagiulia Anglani is the radiologist physician who jointly interpreted the MRI portion of the PET/MRI.

Marina Paola Gardiman is the neuropathologist who made the histological diagnosis.

Chiara Briani, Alessandro Della Puppa, and Diego Cecchin wrote the draft of the manuscript.

All the authors helped in the analysis and interpretation of data.

All the Authors have read and approved the final version of the manuscript.

All the Authors report no disclosures.

\section{References}

1. Wilmshurst JM, Barrington SF, Pritchard D, Cox T, Bullock P, et al. (2000) Positron emission tomography in imaging spinal cord tumors. J Child Neurol. 15:465-72.

2. Tomura N, Ito Y, Matsuoka H, Saginoya T, Numazawa SI, et al. (2013) PET Findings of Intramedullary Tumors of the Spinal Cord Using [18F] FDG and [11C] Methionine. AJNR Am J Neuroradiol 34: 1278-1283. [Crossref]

Copyright: (C2018 Cecchin D. This is an open-access article distributed under the terms of the Creative Commons Attribution License, which permits unrestricted use, distribution, and reproduction in any medium, provided the original author and source are credited. 